ISSN 2076-0752

www.mdpi.com/journal/arts

Article

\title{
Movement and Time in the Nexus between Technological Modes with Jean Tinguely's Kineticism
}

\section{Christina Chau}

The University of Western Australia, 35 Stirling Highway, Perth, Western Australia 6009; E-Mail: christina.chau@uwa.edu.au; Tel.: +61 0864887218

External Editor: Dr. Andres Pardey

Received: 25 April 2014; in revised form: 13 August 2014 / Accepted: 12 September 2014 /

Published: 11 December 2014

\begin{abstract}
This paper addresses auto-destructive artworks by Jean Tinguely, Homage to New York (1960) and Study for an End of the World No. 2 (1962), to explore a changing consciousness of time in a period of technological transition from modern industrial machines towards the domestication of televisual devices. One effect of these is works is a contribution to a turbulent consciousness of time by orchestrating new perceptions of temporality with mechanical and tele-communicational media. Tinguely's kineticism is useful for articulating how different technologies can be used to rationalize time in different ways and highlight an incompatibility between the expression of time as an unfolding duration with mechanical media, and the temporal demands of televisual broadcast media.
\end{abstract}

Keywords: kinesis; kineticism; Jean Tinguely; temporality

\section{Introduction}

The 1960s is marked as a key decade that grappled with technological, social, and political transition and has been described as a "turbulent era" [1] (pp. x), which experienced a "peculiar form of acceleration" [2] (p. 99). Contemporary art historians have at times considered kinetic art in the 1960s as a brief yet popular tendency in Europe and North America that experimented with the movement of mechanical media [3]. As Yve-Alain Bois has recently stated, kinetic sculpture during this time was a phase that came and dissipated quickly due to the antiquation of modern industrial media in a new technological age [4] (p. 145). 
However, avant-garde kinetic sculpture continues to be a site for exploring the "peculiar acceleration" of modernity and its influence over the conceptualizations of movement, time, speed, and acceleration in the present day [2]. While art historian Charlie Gere has recently argued that the artistic responses to the increasingly accelerated society throughout the nineteenth century is a significant element of modern art [5], the 1960s is an especially important decade of debate on the role of time in art as it is the nexus between two technological societies. Rather than a chronophobic understanding of the role of movement and time in kinetic art in the $1960 \mathrm{~s}$ as presented by Pamela Lee in Chronophobia: On Time in the Art of the 1960s [6], it is also useful to consider kinetic art as a tool for expanding the role of temporality in a context of technological turbulence. This paper identifies the 1960 s as a period with an uncertain relationship to time in art that reflects a wider social and technological transition in society. This period is considered as a decade of temporal turbulence, where Jean Tinguely used kinesis to reflect on this technological transition, but more importantly, expanded the role, effects, and changing concepts of time in art.

First, this paper will address the 1960 s as a decade that is marked by a temporal turbulence, where the role and function of time in art was debated and experimented with utopianism, uncertainty, and resistance. The use of new technological media in art was often used as a gateway to discuss the changing conceptions of temporality in society, which brought new perceptions of the role of time and technology for an increasingly ontologically unstable definition of a work of art [6] (pp. 156-184]. Secondly, Michael Fried's essay, "Art and Objecthood" is a quintessential example of the turbulent relationship to time in art that was expressed during this period. Fried's perspective presents the hesitancy towards open durational artworks, because he considers the experience of duration in painting and sculpture as a threat to modern formalist understandings of a work of art [7] (pp. 149-172).

Finally, while Tinguely's early kinetic performances Homage to New York (1960) and A Study for an End of the World (1961/1962) are often addressed as critiques of capitalist production and consumption [8], in this paper I will highlight these auto-destructive works as performances that orchestrate specific experiences that draw out and make viewers sensitive to the unfolding of duration. In both works, Tinguely brings an awareness of the passing present to the fore, and problematizes Fried's argument against durational works of art. Tinguely's use and manipulation of movement in these works indicates a desire to explore the changing conceptions of time that emerged through the experimentation of the new technological media that emerged after World War II. These destructive mechanical performances also present the potentiality for exploring the incompatible rationalizations of time between modern industrial and telecommunication technologies. In effect, Tinguely's work explored the capacity for kinetic art to present nuances between different technological rationalizations of temporality, as well as a means of bringing awareness to, expanding, and complicating the perceptions of duration.

\section{Against Duration: Polemics of Time and Technology in Art in the 1960s}

Avant-garde sculptural artists in Europe and North America in the 1960s began to experiment with the ways in which time could be explored through art. This was evident in areas both inside and outside of kinetic sculpture. As Charlie Gere has argued in Art, Time and Technology, modern art has 
continually formed critiques and reactions to the increasing speed and acceleration of technology in the modern era [5] (p. 13). This suggests that the changing conceptions of temporality are central to the critique and representation of modern acceleration. Lewis Mumford argues precisely this when he states that, rather than the steam engine or any other modern invention, the clock is the most pervasive invention of modernity [9]. This is because the regulation of time mobilized and synchronized the private and public spheres more so than any other modern industrial technology. The regulation of time that commanded the division of labor and leisure implemented a regime of time that influenced the greatest social change of modernity. As Jacques Ellul identifies, all life including the facets of work and leisure, and indeed the perception of change and motion, continues to be approached and governed by the clock [10].

Tinguely's kinetic performances highlight that temporality undergoes a conceptual shift within the emergence of each technological age. In his case, the time codes between industrial machinery, which are fixed in time and space, and the edited rhythms of telecommunications, dislodge and reset the rhythms of the work's destruction.

In 1959, at the Institute of Contemporary Arts in London, Tinguely argued against the traditional representations of time in art, and for his audience to become aware of the experience of the present as it unfolds. Tinguely stated:

The constant of movement, of disintegration, of change and of construction is static. Be constant! Get used to seeing things, ideas and works in their state of ceaseless change. You will live longer. Be permanent by being static! Be part of movement! Only in movement do we find the true essence of things. Today we can no longer believe in permanent laws, defined religions, durable architecture or eternal kingdoms. We are still very much annoyed by out-of-date notions of time. Please, would you throw away your watches! At least, toss aside the minutes and hours [11].

Tinguely addresses time in art as an effective means for critiquing the structural codes of modernity and is used to harness the attention of his audiences in order to engage with his works as experiences rather than representations of time [12]. Time is emphasized as a state of constant change within an objective present [13].

Rather than bringing attention to rationalizations of time, the "kinetic kraze" of the 1960s in Europe and North America has been described as a celebration of the motion of machinic technologies [14]. The technological utopianism of this time also deemed kinetic artists as pioneers of artistic progress. For instance, art historian Jonathan Benthall has reflected that kineticism was "an attempt to develop a theory from which a new art might grow" [15], rather than lamenting early European avant-garde kinetic experiments in art. Leading up to 1970, kinetic sculpture was considered as a popular emerging technological practice that pioneered the experiments between art, science, and technology. Similarly, art critic Katherine Kuh once commented, that "[k]ineticists are space-age artists" who responded to the social and technological turbulence of the time [16]. A strong cohort of artists and exhibitions that discussed new technological artistic practices in the future corroborates this theory [17].

Many have associated kinetic sculpture with material and mechanical abundance, including Jack Burnham [18], Jonathan Benthall [15], Alvin Toffler [19], and Stephen Peterson [20]. While much attention to kinetic art has focused on the materiality and technological experimentation of artists, the popularity and dominance of kinetic art at this time also suggests that it had the potential to foreground anxieties, visualizations, and critiques of changing technological time codes. As Alvin Toffler has 
suggested, the technological expansion after WWII needed to be expressed and critiqued by artists utilizing the same newly domesticated innovations. This provides one explanation of the popularity of kinetic sculpture at this time [19] (p. 156). Therefore, kinesis was not only used to celebrate a machine aesthetic, but also to explore and discuss the sense of accelerated change in modern society.

Additionally, the postmodern aesthetics that were emerging at the end of the 1960s destabilized the notion of time as a central mechanism for regulating society [21]. To follow Jean-Francois Lyotard, postmodernity predominantly works through a framework of reterritorializing the modern power structures [22]. This is achieved by using space as a mechanism for destabilizing this hierarchy [23]. For Jameson, this is further evidenced by the technological shift that has moved from the speed of the mechanical machine towards the instant nature of the digital age [24]. This new transition also prioritized spatial, rather than temporal codes [25], thereby marking the 1960s as a decade of a changing approach to temporality in art.

If, as Jameson has argued, modernity is in part characterized with an "obsess[ion] with the secrets of time," postmodernity is as enamored with space [25]. The 1960s marks a specific nexus in time when the transition between modernity and postmodernity was evident. Jameson's argument can be mirrored through the antonymous reactions to kinetic art in the 1960s. While some regarded kinesis as the newly emerging dominant form of art that celebrated the movement and interaction with technology in art [26], by the end of the decade, the practice was considered to be an obsolete form of modern art [27].

The computer age that emerged during the aftermath of WWII is, amongst others, a key contributor to this acceleration that produced a "peculiar" temporality that differs from the expression of movement earlier in modernity. What is different about the acceleration of the everyday within the computer age is the focus on the speed of information systems. The speed at which information can be presented, distributed, accessed, and processed in the computer age contributes to an increasingly isolated and stationary individual [28]. This is in contrast to the spectacle of movement associated with the modern industrial revolution [29].

Art historian Pamela Lee has argued that artists in this decade of technological transition created art that was sensitive to the "bleak prognosis for the condition of time in late modernity" [6] (p. xi), where the specialization of time became an indication of a transition from modernity to postmodernity [6] (pp. v-xi). Through this, Lee argues that even though temporality was at one point a site of power, it became "understood as at once desperate and fatal" [6] (p. xi). This bleak prognosis, as Lee has described, is a consequence of newly emerging time-space relationships formed by the domestication of technological expansion and increasing presence of the emerging postmodern society [6] (pp. 5-34).

Additionally, despite the enthusiasm in the 1960s for technological progress [25] (p. 6), there was also trepidation towards the consequences of a newly emerging technological society. Technological militarism was a particularly strong incentive for being skeptical of the expansion, domestication, and appropriation of an emerging technological society [30], particularly considering the domestication of war atrocities, international nuclear, and cold war tensions [31]. The culmination of these trepidations and celebrations of technological innovation pinpoints exactly to why Peter Selz described modernity as a "turbulent" era, full of disorientation that artists attempted and struggled to engage with [1] (pp. 275-285). 
Rather than a chronophobic attitude towards the experimentation with technology in art, it is useful to consider kinetic artists who expanded the range and vocabulary for discussing the perception of time in art, rather than simply exploring the form of actual movement. For instance, Willoughby Sharp, the curator of art exhibitions such as Air Art (1968), described kinetic art as the prime medium for elaborating on the effect of time [34]. In Sharp's words the artists in the exhibition titled Air Art, including Graham Stevens, Hans Haacke, Pol Bury, Andy Warhol, Les Levine, and Robert Morris, form works that "create time" [32]. For Sharp, the durational works in the exhibition expand the perceptions of temporality by unfolding in the same time and space as the viewer, inviting them to be a part of a spectacle in real time [32]. Sharp continues, "[k]inetic works are more accurately designated as systems. Their major function is providing information about how to adapt our extended faculties to technology" [32]. For this reason, incorporating time and movement into art provided the potential for further creation and new perspectives of time.

The explorations around time and kinetic movement in art in the 1960s relate to the uncertainty surrounding the emergence of new technologies and in an interrogation of the aesthetic implications of these technologies. While the technological and social changes of this period have warranted descriptions of new conceptions of temporality, peculiar acceleration [2], and even phobic conditions to time-based arts [6] (pp. xi-xxv), these arguments form part of a wider debate that expanded the awareness of the role and affect of real time in art. They have contributed a heterogeneity of understandings that renegotiated time-based arts as real-time systems [32], and open works that responded to the changing perceptions of time in society [33].

One of the most widely discussed critiques against the incorporation of time in art is Michael Fried's essay, “Art and Objecthood." Published in Artforum in 1967, Fried's essay is indicative of an anxiety towards real time in art because it positions duration as a catalyst for destabilizing modern conceptions of a work of art [34] (pp. 166-167). In "Art and Objecthood," Fried argues that duration reduces sculpture to theatricality and prevents the practice from expressing the complexities of modernism. Even though his essay is most explicitly directed towards Minimalism, ABC Art, Primary Structures and Specific Objects, it also represents a critique against artists orchestrating a sense of duration in their art across a variety of disciplines [34] (pp. 166-167).

In "Art and Objecthood," Fried argues that artists were producing works with a specific "objecthood" [34] (pp. 152-153), which is entirely dependent on the reception, interpretation and presence of the viewer [36] (pp. 155-157]. For Fried, this dependency on the viewer to interpret and project meaning onto these pieces reduces the artwork to a mere object, rather than a crafted work of art that has been codified with meaning by the artist. This induces theatricality between the artist and the viewer where "the literalist espousal of objecthood amounts to nothing other than a plea for a new genre of theatre, and theatre is now the negation of art" [34] (p. 153). This creates a slippage between objects of art and non-art, or objecthood, which Fried argues devalued the integrity of sculpture [34] (p. 152).

Fried also proposes that duration has the potential to collapse the plastic arts into theatrical events where "theatre and theatricality are at war today, not simply with modernist painting (or modernist painting and sculpture), but with art as such" [34] (p. 160). Fried is adamant that artists who execute a similar presence or performativity are eroding the quality and status of modern sculpture and must therefore be "defeated" [34] (pp. 167-168). For Fried, a key reason why theatricality in sculpture must 
be abandoned is because of the way durational works are ontologically unstable and unfold in real time with the viewer. In these instances, time is not embedded in the form of the work, but is projected as a seemingly endless present that resides between the viewer and the work of art [34] (pp. 166-168).

Fried is critical of the "sense of temporality, of time both passing and to come, simultaneously approaching and receding, as if apprehended in an infinite perspective," which forms a key concept for his argument against theatricality in sculpture [34] (p. 167). In Fried's words, duration persists in time and the presentment of endlessness that, as I have been claiming, is central to literality art and theory is essentially a presentment of endless or indefinite duration" [34] (p. 167). Therefore, for Fried, a work of art that expresses duration reveals an incompleteness or weakness because it develops with and in the time of its viewers, in contrast to modern painting and sculpture. For Fried, more traditional forms that should be "wholly manifest" have "no duration" and should be created with a specific representation of time that is embedded in the ontological form of the work [34] (pp. 163-165).

Fried's critique affects the interpretation of kineticism in art, particularly artists who were engaging with kinesis as a tool for critiquing society as a spectacle. Instead of experimenting with this, Fried is determined that the formal structures of sculpture should frame time and bind it to the object. This critique against artists who attempt to redefine and restructure the aesthetic of sculpture by exploring expressions of temporality simultaneously makes an attack on the wider practices of technological art, robotics, media art, participatory art, and happenings. Rather than having the potential for creating new emerging artistic practices and emphasizing new differences between them, Fried argues that duration in art conflates and reduces the plastic to the temporal arts.

Fried's argument is indicative of the confusion and debate that circulated the incorporation of real time in art. "Art and Objecthood" presents a polemic for artists experimenting with kineticism as an expression of time because, as Fried argues, duration reduces sculpture to a spectacle of theatricality, which resists a modern definition of a work of art. The shift towards expressing temporality through kinetic dynamism is another indication of the technological change and new means for conceiving and experiencing time in the everyday, in a manner that differs from modern industrial conceptions and practices of time.

\section{Orchestrating Time: Jean Tinguely's Auto-Destructive Machines.}

Tinguely is often recognized in contemporary art history for his neo-realist, neo-dada antagonism and auto self-destructive performances in both Europe and the United States [8] (pp. 67-102), and has since been referred to as the "father of kinetic art" [35]. Tinguely presents a rationale for modern machinery dominating and regulating the times of labor and leisure [36]. However, to only consider the artist's oeuvre as a critique of the modern machine aesthetic suggests that the contemporary exhibition of Tinguely's works is to fetishize modern antiquity and neo-dadaist sensibilities [8]. Another pervasive element of many of Tinguely's works relates to the social engagement with the present temporality as a mode for inciting action, harnessing attention, and manipulating perceptions of duration passing through it. That is, rather than lamenting previously dominant technologies, Tinguely's work also provides a means to reconstruct and expand understandings between time, art and technology. 
From an early age, Tinguely had a fraught relationship with the modern rationalization and regulation of time. For example, before he became an artist, he was fired from a department store for ripping the store clock off the wall before storming out in an act of defiance against the social expectation that time equals money [37] (p. 13). Later, as an artist, Tinguely also resisted the regulation of time in a similar vein. For instance, for the Concert of Seven Pictures at gallery Schmela in Düsseldorf (1959) (also known as Mes Étoiles-Concert Pour Sept Peintures), Tinguely distributed 15,000 copies of his manifesto titled, Für Statik (For Statics) throughout the town via an aircraft. The manifesto called for the honor of actual dynamism and encouraged the production of gestures, motion, and time, in real time, and to abandon forms of static representation in art. The manifesto reads:

Forget hours, seconds, and minutes. Accept instability. Live in Time. Be static-with movement. For a static of the present movement. Live in the present, live once more in time and by Time - for a wonderful and absolute reality. Stop painting "time," live in time and according to time for a wonderful and absolute reality [38].

This manifesto highlights the central principles behind Tinguely's work and follows the avant-garde precedent of destabilizing the traditional modes of representation in art [39]. The manifesto echoes early European avant-garde manifestos, such as Naum Gabo's Realistic Manifesto [40], by calling an attention to and privileging of the present. Tinguely, however, adopts a more critical tone against society for not living in the present, and being distracted by mechanized rationalizations of time instead [11].

In a selection of works, Tinguely has presented duration in a series of repetitious distortions. Radio Sculpture with Feather (1962) and Radio Sculpture Number 5 are both assemblages of recycled machine parts and transmit live radio sounds out into the gallery space [41]. Rather than as a seamless delivery or depiction of the world in time, the radio transmission is fragmented. It fades in and out of range delivering "dismembered" soundscapes that are juxtaposed against the repetitive motions of the mechanical components of the work [42]. Radio Sculpture with Feather is a standing metal box comprised of mechanical parts from different machines and is constructed with an aerial protruding from its head and a feather attached at its end. At repetitive intervals, the sculpture kicks into motion to make the aerial wag wildly in the air above it. Like Radio Sculpture with Feather, Radio Sculpture Number 5 also moves in constant repetitive steps that propel the machine into a machinic performance that is void of producing something other than its movements. Rather than signifying the acceleration of mechanical progress, these works perform hiccupped rhythms of movement.

Unlike Tinguely's self-destructive works, movement and production in Suzuki (1963) and M.K. III (1964) is limited to bursts of repetitive actions and rest. Suzuki is assembled in a contorted arrangement that balances in a top-heavy pose on its mount, while M.K. III is composed with belts that run in continuous loops like empty conveyor belts. By comparison to his auto-destructive performances and antagonist works, these pieces move in a calmer and more regular fashion with their belts looping around and through the sculpture.

In addition to a critique of modern labor and consumption Tinguely also uses spectacles of auto-destructive performances to concentrate on the uneasy relationships his audiences form with the present [8] (p. 172). His mechanical unproductive machines such as Homage to New York and A Study for an End of the World $I$ and $I I$, propose an inquiry of the present temporality that is conveyed 
as entropic and unpredictable in contrast to the rationalized and repetitive movements of modern industrial machinery.

Rather than emphasizing what Pamela Lee describes as a "marked fear of the temporal" in art in the 1960s, Tinguely brings attention to an uneasiness with modern regulation of time in Für Statik. In this manifesto, the artist asks the beholders of his art to confront the time as a mechanically induced regime and attempts to expand and reconstruct perceptions of time by creating new effects with mechanical movement. Therefore, rather than a chronophobic relationship, Tinguely brings attention to the changing attitude towards time that are regulated by technology, and through his kinesis explores and critiques perceptions of time in a period of technological change.

In February 1960, Peter Selz commissioned Tinguely to create his auto-destructive machine Homage to New York, to be performed in MoMA's sculpture garden [43]. Compiled from found scrap metal and junk machinery, pieces of the work were collected from rubbish dumps and mechanical dealers in Newark, Summit, and New York [6] (p. 134). From this accumulation, the final work included eight bicycle wheels, a bassinet, washing machine parts, a weather balloon, piano, radio, American flag and a child's toilet. It was also constructed with multiple sections, each painted in white and programmed to start in motion at its own allocated time. This enabled the entire sculpture to, ideally, turn slowly in separate sections and build into a crescendo of mechanical motion, which would lead to its self-destruction.

On 17 March 1960, the first and only performance of Homage to New York was set into motion, spurring a cacophony of sounds, smells, and mechanical movements. At one stage, a piano played while glass bottles were cast from the top, smashed on the ground and spread nauseating smells while a child's go-cart paced back and forth in front of the work [43] (pp. 74-77). The performance was one of industrial excess. As the artist described, "[t]he machines which we build today produce much more than we can possible consume. I solve this problem of abundance in my own way!" Tinguely emphasized this by making a work that did not produce anything other than motion; a re-staged spectacle of abundance, from abundance [8] (p. 72).

It is no surprise that Homage to New York is remembered as a critique of the physical abundance of consumer materials in capitalist society [39] (p. 493). Tinguely's kinetic performance is also an orchestration of duration, anticipation, and suspense to confront his audience with a new awareness of time. For the experience of the performance itself, one can only draw from the documents, photographs, and film recorded by Robert Breer, as well as firsthand accounts from the audience at MoMA that night that witnessed the sole performance. Billy Klüver, an engineer from Bell Laboratories who assisted Tinguely in the compilation and construction of Homage to New York, reflects on the performance as an experience riddled with interruption, unplanned accidents, and suspense for both the unknowable and yet programmed mechanical self-destruction [43]. In various sections of Klüver's account, he emphasizes the anxiety that he felt while waiting for the work to unfold, and then destroy itself:

Not once did we go over everything and check it; the arm he had worked on with perfection did not work. Something was wrong with it, it was winding too slowly. In the eighteenth minute, the fire extinguisher in the piano was supposed to go off. It didn't. The whole machine was somewhat sick after the bad handling in transport, and it fell over after only a few minutes. After three minutes, the 
longest in my life, they finally began to put out the fire. At this point Jean and I were almost desperate [43].

Klüver's reaction to the unpredictable performance is described as a moment of excruciating suspense and emphasizes Tinguely's manipulation of time - one that draws out, prolongs, and becomes excruciating as a result of anticipation. Some of the sections within the work were delayed, while some began earlier than they were supposed to. For instance, a radio piece played, but the audience could not hear it above the noise of the machine, while some objects rolled in the wrong direction and made paintings out of beer rather than paint, and the overall performance went on for three times longer than Tinguely had anticipated [43] (p. 77). The time that the sculpture took to self-destruct painfully stretched out and tested the threshold between expectation and actualization. In this moment, time waned and slowed because Tinguely brought attention to the uncertainty of time as it unfolded.

Klüver's experience of waiting was an intensive rather than extensive sensation [44]. Throughout the performance, Klüver was not only sensitive to his perception of time, but became arrested in suspense as he waited. This is because for Klüver to wait during Homage to New York was to be seized by it, thus drawing attention to its uncontrollable and unpredictable nature. To wait during the final three minutes before the fire was finally extinguished, Klüver's perception of the passing of time slowed to what felt like an endless state [43]. In a similar vein to the reactions to Tinguely's works at Directions in Kinetic Art, Klüver was void of agency other than being made aware of his impatience, uneasiness, and uselessness. Through Klüver, Tinguely's work is characterized by unease with the present temporality as it is framed as something that is unpredictable, uncertain, and endless.

The uneasiness that Tinguely creates not only exists because the performance heightens an awareness of duration by audience members, but also because Tinguely's kinesis brings forward and makes visible movement as a material and excessive element. This is also emphasized by Selz, who states that a key effect of Tinguely's kineticism is his ability to create a specific relationship between mechanical movement and time. In Selz's words: “Jean Tinguely's experiments are works of art in which time, movement, and gesture are demonstrated - not merely evoked," which resonates with Tinguely's earlier claims in Für Statik [6] (p. 137).

Kinesis is therefore used by Tinguely to present a polemic with the mechanical regulation of time. This is achieved in Homage to New York by bringing attention to the tensions between rationalized time and time as a state of transformation. In addition, Homage to New York is considered as an allegorical performance that celebrates the gradual emerging antiquity of modern rationalizations of time [6] (pp. 133-138). While the exploding self-destructive machine as a commemoration for the end of modern industrial machinery [45], Tinguely also demonstrates that in the wake of technological transition, the conceptions of time-space relationships are also changing within this greater technological and social shift. To create a mechanical landscape out of an abundance of recycled and rejected machinery is not only a warning for the increasing antiquity of modernity, but also acts as a signpost for the new ways time is spent, divided, expressed, and perceived.

The duration of Tinguely's work is characterized by waiting for change that does not happen when it is expected (and also happens when unexpected). Although Klüver lived through the performance, his perception of time was paced by his own hesitancy and passive inaction in a moment of uncertainty. Klüver's hesitancy is evidently a reaction that is indicative of the anticipation and anxiety about change that occurs later than expected, and outside of any control. Tinguely uses movement to 
create a spectacle of motion that arrests its audience with shock and attention through kinesis. Although the work inevitably self-destructed, Klüver's shock originates in the way the mechanical machine moved in unpredictable ways. Tinguely's cacophony of simultaneous motions in Homage to New York also contributes to an open and distributed experience of time.

Perceptions can be heightened when attention to the temporal present is harnessed in the moment. Rather than considering that perception is an act of the subject drawing percepts away from the object, perception is distributed and accumulated over time. The perception of the spectacle within the present has an unavoidable intensity; as Tinguely suggests: "only in movement do we find the true essence of things" [46]. Tinguely emphasizes that modern industrial mechanical movement has the productive potential to pull in an awareness of duration, rather than being a technological tool for abstraction and reproduction. While Homage to New York may have achieved a desired effect, as evidenced by Klüver's reaction, Tinguely's subsequent works highlight the incompatible time codes that exist between technological rationalizations of time, bringing awareness back to the passing of real time.

Following Homage to New York in 1960, Tinguely created two more self-destructive works entitled, A Study for an End of the World (numbered I (1961) and II (1962)). The first was installed at the Louisiana Museum of Modern Art in Humlebaeck, in Denmark, in the exhibition entitled Movement in Art. The second, A Study for an End of the World, was commissioned by NBC's television series David Brinkley's Journal, and was performed in the Mojave Desert near Las Vegas, Nevada in 1962. The work is significant for proposing a critique against modern industrial spectacles of time and production, as well as the domestication of television and telecommunications that became emblematic of the middle-class modern American lifestyle.

Like Homage to New York, the materials that formed A Study for an End of the World II were sourced from nearby garbage dumps in Las Vegas and controlled by Tinguely. It also comprised several sections that were programmed to set into motion at a specific time before exploding entirely. Even though A Study for an End of the World II was created with more sophisticated control mechanisms than Homage to New York, the performance was disrupted by more technical glitches and the entire destruction took an hour longer than it had been programmed to. The spectacle of $A$ Study for an End of the World differs greatly to Homage to New York, precisely because of the conflicting demands between the unfolding mechanical performance and the televised broadcast that the performance was subject to. Even though Homage to New York was recorded with media photographers and captured on film by kinetic sculptor Robert Breer, all documentary media were used to capture the movement and time rhythms of the sculpture itself.

In contrast, A Study for an End of the World brought to the foreground the incompatible schedules between modern industrial machinery and the newly domesticated telecommunications technology that ran at different time schedules. Tinguely highlighted the pressure and failure of modern industrial machinery and rudimentary robotics to keep in time and pace with the televisual broadcast of $A$ Study for an End of the World. The televised documentation of the performance prevented the viewers from witnessing the actual pace and rhythm of the work's unfolding destruction. The spectacle was edited, spliced, and re-presented according to NBC's own temporal demands that conflicted with the unfolding present. While the televised broadcast of this performance distorted the experience and duration of the performance, the culmination of conflicting technological modes in A Study of the End of the World II highlights the intersections and incompatibilities between various technological 
regulations of time, and highlights the peculiar nuances of time performed regulated by each technological age.

\section{Conclusions}

The spectacle that Tinguely orchestrates in A Study for an End of the World II differs from Homage to New York because of the conflicting time schedules that the later performance was subjected to. Even though Homage to New York was recorded by media photographers and captured on film by a number of people present, including kinetic artist Robert Breer, all media was used with the aim of following and documenting the movement and time rhythms of the sculpture itself. A Study for an End of the World II highlights the incompatible schedules between modern industrial machinery and the newly domesticated telecommunications technology. This is emphasized by the pressure and failure of the performance to keep in time and the pace with the televised broadcast. A Study for an End of the World II was marked with an expectation around the pace and synchronicity of various technologies coming together that was not prevalent in Homage to New York. Broadcast to viewers, the televised documentation of the performance prevented its audience from witnessing the actual intensity, pace and rhythm of the work's destruction.

The conflicting experiences of movement and time within and between these works are indicative of a larger turbulent relationship between time and art in this period. Tinguely's works are useful for considering that a key affect of kineticism in art is the ability to express and explore conceptions of temporality through various technological media. As argued in this paper, Tinguely produced works that confronted his audiences with frustrating experiences in time to highlight the tensions and conflicts that emerge between the movement of modern machinery and the transmission of telecommunication technologies.

Tinguely's works can be considered as exploring how time can be regulated and codified by a variety of technological media. It is through Homage to New York specifically that, when attention is brought towards the present temporality in these works, the uneasy and unpredictable nature of time is emphasized. Tinguely articulates the transition from an industrial age towards a new mechanical age by confronting his audiences with their awareness of duration, as well as the manipulation of time by mechanical and communication technologies. His kinetic performances therefore build new perceptions of time, and provide openings for how temporality can be discussed in new ways.

The uneasiness with time in each of Tinguely's performances also mirrors the polemics around time in art in the 1960s. While Fried's essay "Art and Objecthood" from 1967 stands as a key document in contemporary art history arguing against the experimentation with time in art, in an attempt to preserve the ideals of high modernism, his argument fails to acknowledge the social and technological contexts in which time-based arts are made. Therefore, rather than a chronophobic reading of Tinguely's works, Homage to New York and A Study for an End of the World II are useful for building sensitivity to kineticism as a tool for exploring the expression and regulation of time with technological media in art.

\section{Conflicts of Interest}

The author declares no conflict of interest 


\section{References}

1. Selz, P. Art in a Turbulent Era; Ann Arbor: Michigan, MI, USA, 1985; pp. x-xvi.

2. Althusser, L.; Balibar, É. Reading Capital; NBL: London, UK, 1970; p. 99; translated by B. Brewster.

3. Popper, F. Origins and Developments of Kinetic Art; Studio Vista: London, UK, 1968.

4. Bois, Y.A. Force Fields: Phases of the Kinetic. Artforum 2000, 39, 145.

5. Gere, C. Art, Time, Technology; Berg Publishers: Oxford, UK, 2006; p. 2.

6. Lee, P. Chronophobia: On Time in the Art of the 1960s; The MIT Press: Cambridge, MA, USA, 2004.

7. Fried, M. Art and Objecthood: Essays and Reviews; University of Chicago Press: Chicago, IL, USA, 1998; pp. 149-172.

8. Carrick, J. Nouveau Réalisme, 1960s France, and the Neo-avant-garde: Topographies of Chance and Return; Ashgate: Farnham, Surrey, Germany, 2010.

9. Mumford, L. Art and Technics; Columbia University Press: New York, NY, USA, 1952; p. 8.

10. Ellul, J. The Technological Society; Vintage Books: New York, NY, USA, 1967; pp. 329-330.

11. Tinguely, J. "Static, Static, Static!" Conference at the Institute of Contemporary Arts, London, UK, November 1959.

12. Krauss, R. Passages of Modern Sculpture; Thames \& Hudson: London, UK, 1977; pp. 201-242.

13. Bergson, H. Time and Free Will: An Essay on the Immediate Data of Consciousness; Macmillan: London, UK, 1910; pp. 75-139; translated by F.L. Pogson, S. Sonnenchein.

14. Anonymous. Styles: The Movement Movement. Time 1966, 87, 66-69.

15. Benthall, J. Science and Technology in Art Today; Praeger Publishers: New York, NY, USA, 1972; pp. 218-214.

16. Kuh, K. "Recent Kinetic Art". In Nature and Art of Motion; Studio Vista: New York, NY, USA, $1965 ;$ p. 116.

17. Collins Goodyear, A. György Kepes, Billy Klüver and American Art of the 1960s: Defining Attitudes Toward Science and Technology. Sci. Context 2004, 17, 611-635.

18. Burnham, J. Beyond Modern Sculpture: The Effects of Science and Technology on the Sculpture of this Century; G. Braziller: New York, NY, USA, 1968; pp. 218-224.

19. Toffler, A. Future Shock; The Bodley Head: London, UK, 1970; pp. 156-158.

20. Peterson, S. Space-Age Aesthetics: Lucio Fontana, Yves, Klein, and the Postwar European Avant-Garde; Pennsylvania State University Press: University Park, PA, USA, 2009; pp. 1-45.

21. Jameson, F. The Sixties without Apology; University of Minnesota Press: Minneapolis, MI, USA, 1984; pp. 178-209.

22. Lyotard, J.; (trans.) Bennington, G.; Massumi, B. The Postmodern Condition: A Report on Knowledge; Manchester University Press: Manchester, UK, 1984; pp. xvi-xx.

23. Soja, E. Heterotopologies: A Remembrance of Other Spaces in the Citadel-LA. In Postmodern Cities \& Spaces; Watson, S., Gibson, K., Eds.; Blackwell: Oxford, UK, 1995; p.21.

24. Jameson, F. The Seeds of Time; Columbia University Press: New York, NY, USA, 1994; pp. 821.

25. Jameson, F. End of Temporality. Crit. Inq. 2003, 29, 697.

26. Sandberg, W. For Movement's Sake. Newsweek March 13 1961, 9. 
27. For instance, Clement Greenberg described machinic art as an ineffective means of "non-art", "The look of machinery is shunned now because it does not go far enough towards the look of non-art, which is presumable an 'inert' look that offers the eye minimum of 'interesting'." See: Greenberg, C. Modernism with a Vengeance; University of Chicago: Chicago, IL, USA, 1986; p. 252.

28. Crary, J. Suspensions of Perception: Attention, Spectacle and Modern Culture; The MIT Press: Cambridge, MA, USA, 1999.

29. Debord, G. Society of the Spectacle; Black and Red: Detroit, MI, USA, 1977.

30. Jamison, F.; Eyerman, R. Seeds of the Sixties; University of California Press: Berkeley, CA, USA, 1994; p. 6.

31. Virilio, P.; The Art of the Motor; trans. Rose, J.; University of Minnesota Press: Minneapolis, CA, USA, 1995; pp. 133-156.

32. Sharp, W. Air Art; Kineticism Press: New York, NY, USA, 1968; p. 6.

33. Eco, U. The Open Work; Harvard University Press: Cambridge, MA, USA, 1989; pp. 85-87.

34. Fried, M. Art and Objecthood. Artforum 1967, 5, 12-23.

35. Pakesch, P. Commentary on the Works from 1959 until Today. In Moving Parts: Forms of the Kinetic; Museum Tinguely: Graz, Austria, 2005; p. 64.

36. Hultén, P. The Machine as Seen at the End of the Mechanical Age, December 1968. Available online: http://www.moma.org/docs/press_archives/4160/releases/MOMA_1968_JulyDecember_0092_134.pdf?2010_(accessed on 1 May 2012).

37. Hultén, P. A Magic Stronger than Death; Thames \& Hudson: Venice, Italy, 1987.

38. Tinguely, J. Für Statik 1959. In 100 Artists' Manifestos: From the Futurists to the Stuckists; Danchev, A., Ed.; Penguin: London, UK, 2011; pp. 336-337.

39. Cabañas, K. Homage to New York-MoMA: Jean Tinguely's Destructive Art. Available online: http://www.moma.org/explore/multimedia/audios/11/4679 (accessed on 15 January 2013).

40. Gabo, N.; Hammer, M.; Lodder, C. Realistic Manifesto. In Gabo on Gabo: Texts and Interviews; Artist Bookworks: Sussex, UK, 2000; pp. 123-125.

41. Radio Skulptur. Museum Tinguely. Available online: http://www.tinguely.ch/en/museum_sammlung/ sammlung.1960-1969_01112.html (accessed on 14 January 2012).

42. Selz, P. Directions in Kinetic Sculpture: From George Rickey to Jean Tinguely. Available online: http://www.bampfa.berkeley.edu/podcasts/ATC/selz (accessed on 4 March 2012).

43. Klüver, B. The Garden Party. In A Magic Stronger than Death; Hulten, P., Ed.; Thames and Hudson: Venice, Italy, 1987; pp. 74-77.

44. Deleuze, G.; Bergsonism; Zone Books: New York, NY, USA, 1991; pp. 74-76; translated by H. Tomlinson, B. Habberjam.

45. Hoptman, L. What is Useless Science? MoMA 2000, 3, 8-9.

46. Tinguely, J. Dynamo Tinguely. In Zero; Piene, O., Mack, H., Eds.; The MIT Press: Cambridge, MA, USA, 1973; p. 119; translated by H. Beckman.

(C) 2014 by the authors; licensee MDPI, Basel, Switzerland. This article is an open access article distributed under the terms and conditions of the Creative Commons Attribution license (http://creativecommons.org/licenses/by/4.0/). 